\title{
Optimal Time of Extraction Retrievable Inferior Vena Cava Filters in Venous Thromboembolic Treatment: Evidence Based Case Report
}

Akhmadu Muradi ${ }^{1}$, Rudi Hermansyah*2

Background: Inferior vena cava (IVC) filters have been proven to be significantly advantageous and clinically efficacious in the prevention of deathly venous thromboembolism, but also carry long-term risks, such as device failure, filter fracture, migration, penetration into adjacent structures, etc. Retrievable filters offer the same degree of protection, and subsequently lower those risk by removing them after they aren't needed. Unfortunately, increasing use of retrievable filters leads to one alarming trend: there's massive number of filters that are left for an extended time. Whether the time between deployment and retrieval affects filter's technical success of retrieval remains questionable. Here is a case of a 45-year old woman who had undergone retrievable IVC filter due to pulmonary embolism risk. The patient only came to clinician for routine followup once, one month after deployment. One year later, the patient felt abdominal pain and asked to remove the filter. After one failed attempt, the clinician decided to leave the filter in situ as permanent filter.

Method: Literature searching was conducted in several databases (ScienceDirect, EbscoHost, and ClinicalKey) using specified keywords. Six articles that had been passed exclusion and inclusion criteria, were eventually appraised and extracted.

Results: Of all six articles that are included in this study, there are no standard time of retrieval. Each study provides data regarding their attempted retrieval, successful retrieval, and dwell time. Only two articles (Uberoi et al and Glocker et al) analyze the relationship between time of retrieval and successful retrieval. Uberoi et al claims filter retrieval statistically more successful if the dwell time is less than 9 weeks, whereas Glocker et al states the procedure is considerably more successful within 3-4 months ( 117 days) after deployment. The reasons of retrieval failure in these studies are varied, including device angulation, filter incorporation with IVC wall, and penetration to IVC wall and adjacent structures, or significant thrombus inside the filter.

Conclusion: There are no standard time of retrieval, but clinicians could follow FDA recommendation by removing the filter when it isn't necessarily needed. However, a time span of 3-4 months between implantation and retrieval can be respectable choice to make sure the maximum chance at retrieval success.

Keywords: Inferior Vena Cava Filter, Filter Retrieval, Dwell Time, Venous Thromboembolism https://doi.org/10.36864/jinasvs.2021.1.011

*Corresponding author: rudi.hermansyah.1985@gmail.com

${ }^{1}$ Division of Vascular and Endovascular Surgery, Department of Surgery, Faculty of Medicine, University of Indonesia,Dr. Cipto Mangunkusumo National Centra Hospital, Jakarta

${ }^{2}$ Department of Surgery, Faculty of Medicine, Universitas Indonesia, Dr. Tjipto Mangunkusumo General Hospital, Jakarta

\section{INTRODUCTION}

Venous thromboembolism (VTE), manifested as deep vein thrombosis (DVT) or pulmonary embolism (PE), is a fatal disease that $5 \%$ of people are affected during their lifetime. ${ }^{1}$ One-third of venous thromboembolism cases turn into PE, while others become DVT. Anticoagulant management of such cases, which has been applied for decades, doesn't appear to reduce the mortality rate of VTE. According to a study, one month-mortality rate of DVT is $6 \%$ and the number is doubled for PE. ${ }^{2}$ Inferior Vena Cava
Copyright (C) 2021, The Indonesian Society for Vascular and Endovascular Surgery

JINASVS 2021;2(1):41-47 


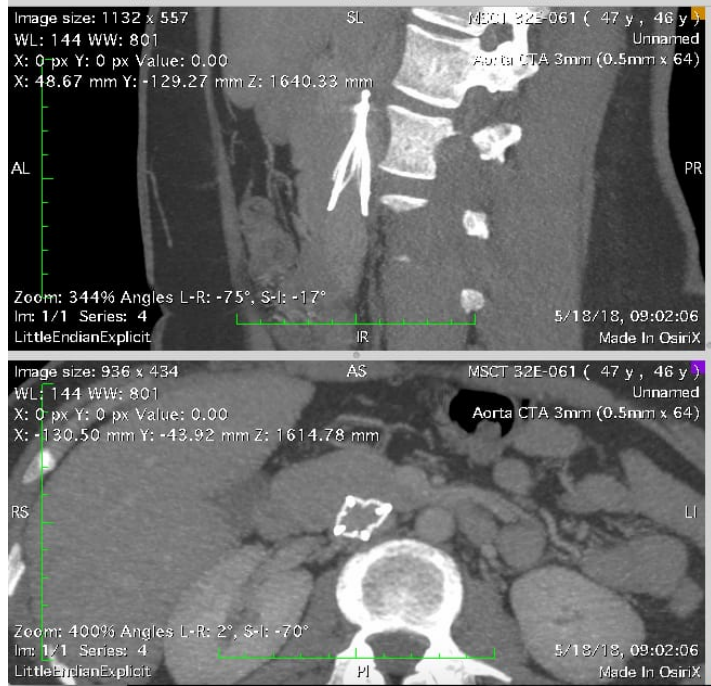

Figure 1. Pre-Retrieval CTA

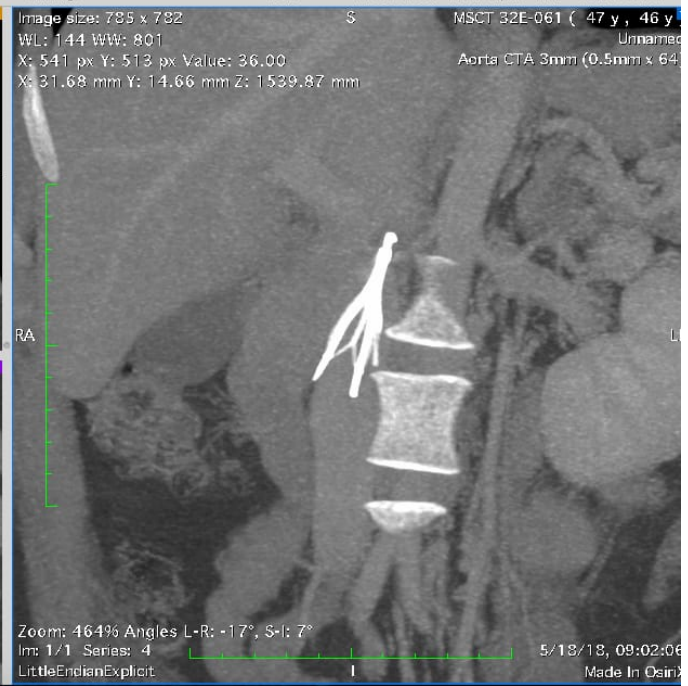

Four days later, the patient came to surgeon's clinic to report her symptoms. The swelling gradually reduced, but she did daily activities without any significant problems. The patient was going to be referred back to Ob-Gyn when the DVT manifestations were resolved. Two weeks later, on the second visit, the initial symptoms of swelling and tenderness were not complained. Anticoagulant was still given on adjustment dose to prevent vaginal bleeding.

In the next two months, the patient was hospitalized two times due to massive vaginal bleeding and received blood transfusion, supervised by the Ob-Gyn.

Four months after IVCF placement, the total hysterectomy and bilateral salpingo-oophorectomy procedure was performed by the Ob-Gyn. One month after this procedure, patient started to feel chest pain and palpitations. Nevertheless, the patient never came to the surgeon to consult these problems.

One year after IVCF placement, the patient came to surgeon with several complaints, such as palpitations, epigastric pain, and itching. The patient asked the IVC filter to be retrieved. The patient and her family were educated about the procedure, including complications and success rate afterwards. CT Angiography was conducted as pre-procedural management. The result showed that the filter didn't migrate, but both its hook and anchor merged into IVC wall. The surgeon explained about filter's condition and the option to leave filter in-situ as permanent type, but they refused and insisted the procedure to be continued. After several attempts, the filter was failed to retrieve. The patient and her family was informed, and they eventually agreed to leave it permanently with its associated risks (e.g. IVC thrombosis and filter migration). After the procedure, the patient returned daily life without problem

\section{CLINICAL QUESTION}

The clinical question in this article is:

"In patient that has undergone retrievable filter placement, when is the optimal time filter retrieval procedure's performed?"

\section{METHOD}

In order to answer the clinical question, a comprehensive computer-based literature search was 
Table 1. Result of Article Search

\begin{tabular}{|c|c|c|c|c|c|c|c|}
\hline No & Writer (Year) & Study Type & $\begin{array}{l}\text { Sample } \\
\text { Size }\end{array}$ & $\begin{array}{l}\text { Number of } \\
\text { Retrievable Filter } \\
\text { Placement }\end{array}$ & $\begin{array}{l}\text { Retrieval } \\
\text { Attempt }\end{array}$ & $\begin{array}{l}\text { Successful } \\
\text { Retrieval (\%) }\end{array}$ & $\begin{array}{l}\text { Level of } \\
\text { Evidence } \\
\text { (LoE) }\end{array}$ \\
\hline 1 & $\begin{array}{l}\text { Tapson, et al } \\
\text { (2017) }\end{array}$ & $\begin{array}{l}\text { Prospective, } \\
\text { clinical study }\end{array}$ & 163 & 163 & $143 / 163$ & $143 / 143(100 \%)$ & II \\
\hline 2 & $\begin{array}{l}\text { Glocker, et al } \\
(2014)\end{array}$ & $\begin{array}{l}\text { Retrospective } \\
\text { study }\end{array}$ & 121 & 636 & $121 / 636$ & $92 / 121(76 \%)$ & II \\
\hline 3 & Lee, et al (2018) & $\begin{array}{l}\text { Retrospective } \\
\text { study }\end{array}$ & 141 & 141 & $\begin{array}{l}\text { 100/141 } \\
\text { Abutting } \\
\text { group: } 37 / 52 \\
\text { Non-abutting } \\
\text { group: } 63 / 89\end{array}$ & $\begin{array}{l}96 / 100 \text { ( } 96 \%) \\
\text { Abutting group: } \\
34 / 37(92 \%) \\
\text { Non-abutting } \\
\text { group: } 62 / 63 \\
(98 \%)\end{array}$ & II \\
\hline 4 & $\begin{array}{l}\text { Stavropoulos, et } \\
\text { al (2016) }\end{array}$ & $\begin{array}{l}\text { Prospective, } \\
\text { clinical study }\end{array}$ & 200 & 200 & $124 / 200$ & $121 / 124(97.5 \%)$ & I \\
\hline 5 & $\begin{array}{l}\text { Uberoi, et ak } \\
\text { (2013) }\end{array}$ & $\begin{array}{l}\text { Retrospective } \\
\text { study }\end{array}$ & 1434 & 721 & $415 / 721$ & $345 / 415(83 \%)$ & II \\
\hline 6 & Reis, et al (2016) & $\begin{array}{l}\text { Retrospective } \\
\text { study }\end{array}$ & 87 & 87 & $31 / 87$ & $31 / 31(100 \%)$ & II \\
\hline
\end{tabular}

conducted on April until Mei 2019 using several databases (ScienceDirect, EBSCOHost, and ClinicalKey). This process use following keywords: ("Venous Thromboembolism" OR "Deep Vein Thrombosis" OR "Pulmonary Embolism") AND ("Retrievable Filter") AND ("Retrieval") AND ("Success Rate") AND ("Timing" OR "Time" OR "Duration"). Several inclusion criteria was applied, including text in English or Bahasa, published in the last six years, and full-text available. All abstracts and title form the initial search was reviewed thoroughly to ensure the selected articles fulfilled both inclusion and exclusion criteria. All relevant studies were appraised using critical appraisal worksheet from Center of Evidence Based Medicine (CEEBM), Oxford University. Valuable information and data from each study was extracted and compiled into one single table.

\section{RESULT}

A total of 29 studies met inclusion criteria after abstract and title screening process in literature search. After reading the full-text version of each study, 23 studies were excluded because several reasons (study design, no desirable information, etc.). In total, there are six studies included in this case report, and all of them were appraised using the criteria from Centre of Evidence-Based Medicine University of Oxford for prognostic studies. All involving studies are described in Table 1 and II.

Glocker, et al conducted a review to determine the optimal time filter retrieval, and factors related to successful procedure. This study included 121 patients that had undergone filter retrieval attempts from 2006 to 2012 in Alabama, US. From those attempted retrievals, 92 filters $(76 \%)$ were successfully retrieved. 26 cases were failed to retrieve due to inability to reach the filter's hook, while another three cases were caused by the inappropriate manner of filter's release. In unsuccessful retrieval group, retrieval procedure took remarkably longer time (mean 49 minutes, SD 17 minutes) than successful retrieval group (mean 29 minutes, SD 14 minutes). Dwell time in this group was also significantly longer (162 days, 43-379 days) than the other group (105 days, 7-368 days). These data was analyzed and projected into Kaplan-Meier curve, and it showed that $90 \%$ of successful retrieval cases had dwell time less than 117 days.

The second study was a multicenter, prospective, single-arm clinical trial from Tapson, et al that investigated filter placement in 20 intensive care unit (ICU) across United States. One hundred and sixty three filters were placed in critically-ill patients that met following criteria: recognized contraindications to pharmacologic thromboprophylaxis and/or confirmed acute lower extremity DVT that contra-indicated to anticoagulant therapy. Nearly all of the samples $(98.2 \%)$ used IVC filter as prophylaxis of pulmonary embolism, and the filters were maintained in IVC for approximately 7 days (mean 7.2 days \pm 3.8 days). Retrieval attempts were performed in $143(88 \%)$ patients, and they were all successful. Mean procedure time was 8 minutes (IQR 4-18 minutes). Large thrombus and small thrombus occurred in $14(8.6 \%)$ samples and 17 $(10.4 \%)$ respectively.

Uberoi, et al, analyzed British Society of Interventional Radiology (BSIR) Inferior Vena Cava Filter (IVC) registry report from October 2007 until March 2011. This report contained data about 1434 filter placement and 400 filter retrieval procedures in 68 centers across UK. Gunther Tulip (39\%) and Celect $(25 \%)$ were the most frequently used filters. Retrievable filters were mainly placed in young adults, pregnant women, or patients with temporary high risk. Cordis OptEase was the filter with the shortest dwell time (median 12 days, 2-45 days), while Bard G 2 was the longest one (median 77 days, 34-154 days). Seventy hundred and twenty one filters were initially placed for temporary placement, and followup data was only available in 514 samples. From the remaining samples, $415(81 \%)$ filters were retrieved with success rate went up to $83 \%$. Cava thrombosis and clinical deterioration were the common reasons for non-retrieved filters. Successful retrieval was highly affected by dwell time. It's reported that filter placement beyond 9 weeks was significantly correlated with failed retrieval, mainly due to incorporation of the device, IVC thrombosis, or penetration by filter's legs. One of the interesting facts in this study was Bard filter had the highest success rate despite its prolonged dwelling time. IVC wall perforation, filter migration, pulmonary embolism, and lower extremity thrombosis were notable long-term complications reported. 
Table 2. Characteristics of Involving Studies

\begin{tabular}{|c|c|c|c|}
\hline $\mathrm{Nu}$ & Writer (Year) & Dwell Time & Factors Related to Failed Retrieval Failure \\
\hline 1 & $\begin{array}{l}\text { Tapson, et al } \\
(2017)\end{array}$ & Mean 7.2 days \pm 3.8 & All filters were retrieved successfully \\
\hline 2 & $\begin{array}{l}\text { Glocker, et al } \\
\text { (2014) }\end{array}$ & $\begin{array}{l}\text { Successful } \\
\text { retrieval: Mean } \\
105 \text { days (7-368 } \\
\text { days) }\end{array}$ & $\begin{array}{l}26 \text { cases were failed to retrieve due to inability to } \\
\text { reach the filter's hook, while another three cases } \\
\text { were caused by the inappropriate manner of filter's } \\
\text { release. Filter angulation }>20^{\circ} \text { was statistically }\end{array}$ \\
\hline & & $\begin{array}{l}\text { Unsuccessful } \\
\text { retrieval: Mean } \\
162 \text { days ( } 43-379 \\
\text { days) }\end{array}$ & $\begin{array}{l}\text { correlated with retrieval failure, found in } 7 \text { out of } 29 \\
\text { failed cases in this study }\end{array}$ \\
\hline 3 & $\begin{array}{l}\text { Lee, et al } \\
(2018)\end{array}$ & $\begin{array}{l}\text { Abutting group: } \\
\text { Mean } 21 \text { days } \\
\text { Non-abutting } \\
\text { group Mean } 23 \\
\text { days }\end{array}$ & $\begin{array}{l}\text { There was no description on failed retrieval reason } \\
\text { on both groups. However, the incidence of retrieval } \\
\text { failure, complex retrieval, and complicated retrieval } \\
\text { was statistically higher. The presence of external } \\
\text { compression of IVC also resulted in higher number of } \\
\text { difficult retrieval case }\end{array}$ \\
\hline 4 & $\begin{array}{l}\text { Stavropoulos, } \\
\text { et al (2016) }\end{array}$ & $\begin{array}{l}\text { Mean } 200.8 \text { days } \pm 156.9(5-736 \\
\text { days) }\end{array}$ & $\begin{array}{l}\text { The reasons of failed retrieval were filter apex hadn't } \\
\text { been engaged successfully ( } 2 \text { cases) and the } \\
\text { existence of blood clot inside the filter ( } 1 \text { case) }\end{array}$ \\
\hline 5 & $\begin{array}{l}\text { Uberoi, et al } \\
\text { (2013) }\end{array}$ & $\begin{array}{l}\text { Bard G: Median } 77 \\
\text { days ( } 34-154 \\
\text { days); Bard } \\
\text { Recovery: Median } \\
77 \text { days ( } 28-166 \\
\text { days) } \\
\text { Cook Celect: } \\
\text { Median } 32 \text { days } \\
\text { (18-66 days); } \\
\text { Cook Gunther } \\
\text { Tulip: Median } 39.5 \\
\text { days (22-101 } \\
\text { days) } \\
\text { Cordis OptEase: } \\
\text { Median } 12 \text { days } \\
\text { (2-45 days) }\end{array}$ & $\begin{array}{l}\text { There was no detailed information regarding failed } \\
\text { retrieval cases. However, failed retrieval case that } \\
\text { had been deployed }>62 \text { days was correlated with } \\
\text { device incorporation with IVC wall, IVC thrombosis, } \\
\text { and penetration of IVC wall by filter legs. }\end{array}$ \\
\hline 6 & $\begin{array}{l}\text { Reis, et al } \\
(2016)\end{array}$ & Mean 125 days (34-324 days) & All filters were retrieved successfully \\
\hline
\end{tabular}

Retrospective study from Reis, et al, on Denali filter placement in Dallas, US. This specific filter was placed in 87 patients, mainly as an alternative option for patients that were contraindicated to anticoagulant. Retrieval attempts were performed in $31(36 \%)$ patients, with mean dwell time of 125 days (34-324 days). All of the filters were successfully retrieved. Post-deployment complications were IVC wall penetration, cava thrombus and occlusion, and filter tilt.

Lee, et al, published a retrospective study on Celect filter placement in South Korea. In this study, samples were divided into two separate groups, patients with filter tip abutment and patients without it. Total retrieval attempt was $100(71 \%)$ in both groups (37/52 in abutting group and 63/89 in nonabutting group). Higher success rate was found in non-abutting group $(98 \%)$, with overall success rate was $96 \%$. This remarkable high success rate compared to other studies was believed to have been correlated with shorter dwell time ( 21 days in abutting group vs 23 days in non-abutting group). Filter tilt $>15^{\circ}$ was the only post-deployment complication that was stated in this study.

Stavropoulos, et al, conducted a multicenter, prospective trial with 200 samples that had undergone Denali filter placement. Placement procedure success rate was $99.5 \%$, with only one sample was failed to deploy due to technical problem. Indications for placement including current vein thromboembolism disease (DVT or PE) or temporary high risk of PE. Retrieval procedure was performed in 124 samples, with success rate percentage went as high as $97.6 \%$ (121 out of 124 ). The reasons of failed retrieval were filter apex hadn't been engaged successfully and the existence of blood clot inside the filter. Mean dwell time was 200.8 days \pm 156.9 (5736 days). Almost half of the filter (46.3\%) had been remained inside IVC more than 180 days. Complication that was found during follow-up included IVC wall penetration during placement and retrieval.

\section{DISCUSSION}

\section{Retrieval Optimal Time}

In recent years, the increasing use of retrievable filter in clinical practice has created several questions regarding its placement. This type of filter, originally, is designed to facilitate its retrieval procedure. In reality, there is growing trend where these filters are left in place for longer time or used as permanent filters. Many studies state that retrieval rate among centers all over the world is as low as $30 \%$. Despite approval from FDA, this institution still recommends filter retrieval as primary choice. It is believed that extended dwell time increases postdeployment complications (filter migration, filter fracture, etc.). Therefore, interventionist should acknowledge when is the optimal time that retrievable filter removal should be performed, to ensure 
minimum risk of complications or retrieval failure later.

This evidence-based case report provides 2146 samples that have undergone retrievable filter placement from six studies. Each study publishes the number of filter placement, filter retrieval attempt, successful retrieval, as well as filter's dwell time.

Prior studies never publish the standard time of filter retrieval, and neither do the studies in this report. Only two studies (Uberoi, et al, and Glocker, et al) analyze the relationship between dwell time and success rate of retrieval procedure, while remaining studies only provide data regarding their success rate and mean dwell time.

In Uberoi's study, retrieval procedure statistically more successful in the first 9 weeks (62 days). This study also provided dwell time from each type of filter that was recommended by its manufacturer (BBraun $<12$ weeks, Celect $<67$ weeks, Gunther Tulip $<20$ days, OptEase $<23$ days, Pyramed ALN $<25$ months). Interestingly, many retrieval failure cases occurred within the time period. ${ }^{31}$ Meanwhile, Glocker, et al, found that the duration of filter's placement was significantly different between successful retrieval and unsuccessful retrieval (105 days vs 162 days). This study stated that extended filter's dwell time was a predictor of filter retrieval failure in the future, other than filter angulation more than $>20^{\circ}$. Retrieval procedure prior than 117 days had success rate up to $90 \% \cdot{ }^{35} \mathrm{~A}$ study in US showed that success rate could be as high as $98 \%$, with time to retrieval interval was 4.6 months \pm 4.3 months. ${ }^{39}$ Another study found that dwell time $>90$ days was correlated with higher number of retrieval failure cases. ${ }^{32}$

Other studies in this report had contrasting perspectives. Two studies, Tapson, et al, and Lee, et al, had shorter dwell time ( $<30$ days) with retrieval success rates were more than $90 \%$. Meanwhile, the other studies, Stavropoulos, et al, and Reis, et al, had similar success rates with much longer dwell time (200 days \pm 156.9 and 125 days). Both studies used an exact type of filter, Denali filter that was recently launched in the market.

Based on these studies, retrieval procedure could be considered around three to four months after placement to achieve significant success rate. However, the recommendation from FDA that filter retrieval should take place as soon as possible when bleeding risk diminishes to start anticoagulant therapy, can be prioritized. One of the key reasons is to prevent loss-to-follow up cases that normally occur when dwell time is prolonged. Therefore, interventionist should design follow-up strategies that are strict yet effective. Few examples are establishing patient-based-registry and 30-days routine control program. Then, the clinician, the patient and his/her family members, can discuss the ideal time of retrieval procedure together. Furthermore, patients that don't show up during routine control, can be contacted personally after cross-checking in the registry. These methods are proven to be effective to improve patients' adherence during follow in several institutions. ${ }^{39}$

\section{Factors Related to Retrieval Failure}

Prolonged dwell time is well-known to result in several complications, such as filter fracture, IVC wall perforation, filter migration, or thrombosis. Belkin, et al, showed that filter that had been remained too long is key predictor of retrieval failure. ${ }^{39}$ Prior studies have demonstrated the main reason of failed retrieval is filter tilt, when tip of the filter contacts IVC wall. ${ }^{30}$ This finding is in accordance with another two respective studies in US, when filter tilt is correlated with advanced retrieval and retrieval failure. ${ }^{40,41}$ From studies that are included in this report, there are only four articles that have reported retrieval failure cases. Glocker, et al, showed that there was a relationship between retrieval failure and filter angulation more than $20^{\circ}$. Meanwhile, Stavropoulos, et al, stated that there were two factors related to retrieval failure, the inability to reach the filter due to anatomical curvature and thrombus inside the filter. Filter incorporation with IVC wall, IVC penetration, and filter thrombus were reasons in failed retrieval cases with prolonged dwell time ( $>62$ days).

Studies that are included in this evidencebased case report have several limitations regarding filter retrieval. One of them is majority of the study doesn't set the optimal time of filter retrieval as primary outcome of the study, making it difficult to analyze two key variables (dwell time and success rate). Furthermore, studies with high number of retrieval failure don't explain in detail the reason for each case. Most of them only describe it in quite short sentences. Therefore, finding conclusion on this topic is rather difficult.

\section{CONCLUSION}

The conclusion of this evidence-based case report is six studies are matched with case illustration and clinical question based on literature search and study appraisal. They are four retrospective studies and two prospective, clinical studies. There is no single guideline that has published optimal time of filter retrieval procedure, therefore interventions should consider retrieve the filter as soon as possible when it is no longer needed, according to FDA recommendation. This report has showed that dwell time up to 4 months is still considered safe to prevent any technical failure on retrieval. The time limit can be used in terms of clinical setting when follow-up strategy is not established yet.

Factors that are known affect retrieval failure include filter tilt, filter incorporation with IVC wall, and penetration from filter component into IVC.

\section{CONFLICT OF INTEREST}

The author states the original work, and there is no conflict of interest in doing this research.

\section{ORCID ID OF AUTHORS}

\section{REFERENCES}

1. Spencer FA, Emery C, Lessard D, Anderson F, Emani S, Aragam J, dkk. The Worcester Venous Thromboembolism Study. A population based study of the clinical epidemiology of venous thromboembolism. J Gen Intern Med. 2006;21(7):722-7

2. White RH. The epidemiology of venous thromboembolism. Circulation. 2003;107:14-8 
3. Stein PD, Matta F, Hull RD. Increasing use of vena cava fiters for prevention of pulmonary embolism. Am J Me. 2011;124(7):655-61

4. Andreoli JM, Lewandowski RJ, Vogelzang RL, Ryu RK. Comparison of complication rates associated with permanent and retrievable inferior vena cava fiters: a review of the MAUDE database. J Vasc Interv Radiol. 2014;25(8):1181-5

5. Angel LF, Tapson V, Galgon RE, Restrepo MI, Kaufman J. Systematic review of the use of retrievable inferior vena cava filters. J Vasc Interv Radiol. 2011;22(11):1522-30

6. Ku GH, Billett $\mathrm{HH}$. Long lives, short indications. The case for removable inferior cava filters. Thromb Haemost. 2005;93(1):17-22

7. Chiou AC. IVC filter retrieval: Long-term data on today's filter are needed. Endovasc Today. 2005;4:81-4

8. US Food and Drug Administration. Removing retrievable inferior vena cava filters: FDA safety communication. [Internet]. [Accessed May 20 2019]. Available at: http://www.fda.gov/MedicalDevices/Safety/AlertsandNotices/ucm396377.htm

9. Dowell JD, Castle J, Schickel M, Andersson UK, Zielinski R, McLoney E, dkk. Celect inferior vena cava wall strut perforation begets additional strut perforation. J Vasc Interv Radiol. 2015;26:1510-8

10. Ochsner JL, McFadden PM. A history of diagnosis and treatment of venous thromboembolism and pulmonary embolism. The Ochsner J. 2002;4(1):9-13

11. Heit JA. Epidemiology of venous thromboembolism. Nat Rev Cardiol. 2015;12(8):464-74

12. Søgaard KK, Schmidt M, Pedersen L, Horváth-Puhó E, Sørensen HT. 30-year mortality after venous thromboembolism: a population-based cohort study. Circulation. 2014;130(10):829-36

13. Anderson FA, Spencer FA. Risk factors for venous thromboembolism. Circulation. 2003;107(23):19-16

14. Moheimani F, Jackson DE. Venous thromboembolism: classification, risk factors, diagnosis, and management. ISRN Hematol. 2011;2011:124610

15. Wells PS, Anderson DR, Bormanis J, Guy F, Mitchell M, Gray L, dkk. Value of assessment of pretest probability of deep-vein thrombosis in clinical management. Lancet. 1997;350:1795-8

16. Mazzolai L, Aboyans V, Ageno W, Agnelli G, Alatri A, Bauersachs R, dkk. Diagnosis and management of acute deep vein thrombosis: a joint consensus document from the European society of cardiology working groups of aorta and peripheral circulation and pulmonary circulation and right ventricular function. Eur Heart J. 2018;39(47):4208-18

17. Stein PD, Fowler SE, Goodman LR, Gottschalk A, Hales CA, Russell D, dkk. Multidetector computed tomography for acute pulmonary embolism. N Eng J Med. 2006;354(22): 2317-27

18. McRae SJ, Eikelboom JW. Latest medical treatment strategies for venous thromboembolism. Expert Opin Pharmaco. 2007;8(9): 1221-33

19. The CLOTS (Clots in Legs Or sTockings after Stroke) Trial Collaboration. Thigh-length versus belowknee stockings for deep venous thrombosis prophylaxis after stroke: a randomized trial. Ann Intern Med. 2010; 153(9):553-62

20. Long JB. Venous thromboembolism: pharmacological and nonpharmacological interventions. J Cardiovas Nurs. 2009;24(6):S8-S13

21. Craven P, Daly C, Oates R, Sikotra N, Clay T, Gabbay E. Inferior vena cava filters (IVCFs): a review of uses and application to international guidelines at a single Australian center; implications of venous thromboembolism associated with malignancy. Pulm Circ. 2018;8(2):1-9

22. Smouse BJ, Johar A. Is market growth of vena cava filters justified? Endovasc Today. 2010:74-7

23. Wassef A, Lim W, Wu C. Indications, complications and outcomes of inferior vena cava filters: A retrospective study. Thromb Res. 2017;153: 123-8

24. Marquess JS, Burke CT, Beecham AH, Dixon RG, Stavas JM, Sag AA, dkk. Factors associated with failed retrieval of the Günther Tulip inferior vena cava filter. J Vasc Interv Radiol. 2008;19(9):1321-7

25. US Food and Drug Administration. Safety Communications - Removing Retrievable Inferior Vena Cava Filters. Initial Communication. [Internet]. [Accessed 20 May 2019]. Available at: http://www.fda.gov/MedicalDevices/Safety/AlertsandNotices/ucm221676.htm

26. Montgomery JP, Kaufman JA. A critical review of available retrievable inferior vena cava filters and future directions. Semin Intervent Radiol. 2016;33:79-87

27. Holly BP, Funaki B, Lessne ML. Inferior vena cava filters why, who, and for how long? Clin Chest Med. $2018 ; 39(3): 645-50$

28. Laws JL, Lewandowski RJ, Ryu RK, Desai KR. Retrieval of inferior vena cava filters: technical considerations. Semin Intervent Radiol. 2016;33(2):144-8

29. Jia Z, Fuller TA, McKinney JM, Paz Fumagalli R, Fret GT, Sella DM, dkk. Utility of retrievable inferior vena cava filters: a systematic literature review and analysis of the reasons for nonretrieval of filters with temporary indications. Cardiovasc Intervent Radiol. 2018;41(5):675-82

30. Lee SY, Lee J. Is external compression on the IVC a risk factor for IVC filter abutment? A single center experience of 141 infrarenal celect filter insertions. Eur J Radiol Open. 2018;5:73-8

31. Uberoi R, Tapping CR, Chalmers N, Algar V. British society of interventional radiology (bsir) inferior vena cava (ivc) filter registry. Cardiovasc Intervent Radiol. 2013;36(6):1548-61

32. Eisbusch P, Benenati JF, Pena CS, Couvillon J, Powell A, Gandhi R, dkk. Retrievable inferiorvena cava filters: factors that affect retrieval success. Cardiovasc Intervent Radiol. 2012;35(5):1059-65

33. Decousus H, Leizorovicz A, Parent F, Page Y, Tardy B, Girard P, dkk. A clinical trial of vena caval filters in the prevention of pulmonary embolism in patients with proximal deep-vein thrombosis. Prevention du Risque d'Embolie Pulmonaire par Interruption Cave Study Group. N Engl J Med. 1998;338:409-15

34. Spencer FA, Bates SM, Goldberg RJ, Lessard D, Emery C, Glushchenko A, dkk. A population-based study of inferior vena cava filters in patients with acute venous thromboembolism. Arch Intern Med. 2010;170(16):1456-62 
35. Glocker RJ, Novak Z, Matthews TC, Patterson MA, Jordan WD, Pearce BJ, dkk. Factors affecting cook gunther tulip and cook celect inferior vena cava filter retrieval success. J Vasc Surg:Venous and Lym Dis. $2014 ; 2(1): 21-5$

36. Tapson VF, Hazelton JP, Myers J, Robertson C, Gilani R, dkk. Evaluation of a device combining an inferior vena cava filter and a central venous catheter for preventing pulmonary embolism among critically ill trauma patients. J Vasc Interv Radiol. 2017;28(9):1248-54

37. Reis SP, Kovoor J, Sutphin PD, Toomay S, Trimmer C, Pillai A, dkk. Safety and effectiveness of the Denali inferior vena cava filter: intermediate follow-up results. Vasc Endovasc Surg. 2016;50(6):38590

38. Stavropoulos SW, Chen JX, Sing RF, Elmasri F, Silver MJ, Powell A, dkk. Analysis of the final Denali trial data: a prospective, multicenter study of the Denali inferior vena cava filter. J Vasc Interv Radiol. 2016;27(10):1531-8

39. Belkin N, Jackson BM, Foley PJ, Damrauer SM, Kalapatapu V, Golden MA, dkk. Trends in inferior vena cava filter placement and retrieval at a tertiary care institution. J Vasc Surg: Venous and Lym Dis. $2019 ; 7(3): 405-12$

40. Dowell JD, Wagner D, Elliott E, Yildiz VO. Factors associated with advanced inferior vena cava filter removals: a single-center retrospective study of 203 patients over 7 years. Cardiovasc Intervent Radiol. 2016;39:218-26

41. Ramaswamy RS, Jun E, Beek DV, Mani N, Salter A, Kim SK, dkk. Denali, tulip, and option inferior vena cava filter retrieval: a single center experience. Cardiovasc Intervent Radiol. 2018;41(4):572-7 